\title{
Enhancing a mobile application with contextual information delivery using proximity beacon: a preliminary study at a tourist destination
}

\author{
Alya Geogiana Buja*, Noor Afni Deraman, Khyrina Airin Fariza Abu Samah, Mohd Nor Hajar \\ Has rol Jono, Mohd Ali Mohd Isa and Shahadan Bin Saad \\ Universiti Teknologi MARA Cawangan Melaka, Faculty of Computer and Mathematical Sciences, Malaysia
}

Received: 10-October-2020; Revised: 08-May-2021; Accepted: 10-May-2021

(C)2021 Alya Geogiana Buja et al. This is an open access article distributed under the Creative Commons Attribution (CC BY) License, which permits unrestricted use, distribution, and reproduction in any medium, provided the original work is properly cited.

\begin{abstract}
This paper presents the development of a mobile application with contextual information delivery using proximity beacon. The aim of this study is to help the tourism industry in attracting more visitors. To execute the functions, a prototype was developed and based at Melaka Zoo, Malaysia. There are two mobile technologies used in the development of the prototype namely geofence and proximity beacon using Bluetooth. There are three phases involved in developing the prototype; feasibility study and requirement analysis, design, and development and testing. The functionality and the network performance of the developed application was successfully tested and validated. All designed and developed functions of the application were working correctly. In addition, the network performance of geofence and beacon were acceptable. Further work is recommended to ensure that the application can be applied successfully in other domains such as smart campus, smart home and smart mall applications. Besides, the development can be extended to the iOS platform.
\end{abstract}

\section{Keywords}

Contextual information, Geofence, Mobile computing, Proximity beacon, Tourism.

\section{Introduction}

Due to the Coronavirus Disease 2019 (or also known as the COVID-19 pandemic), tourism industry is one of the economic sectors that has been seriously affected, leading to closures of numerous tourism operations, organizations, and businesses worldwide $[1,2]$. In order for the tourism industry to continuously survive in this difficult situation, there is a need to come out with new innovations [3, 4], especially the ones that address the requirements in the new norm practices. Hence, the use of mobile applications for disseminating and managing information has become one of the necessary steps that can be taken by the touris mindustry in surviving under the pandemic situation. Since the presentation of the iPhone by Apple Incorporation in 2007 has led towards the new dimension of cell phones and eventually spearheads the production of smart phones that are furnished with advance innovations and sensors that can be modified into mobile applications to perform various complex tasks [5].

\footnotetext{
*Author for correspondence

This work was supported by Universiti Teknologi MARA Cawangan Melaka under TEJA: Internal Grant (GDT2020-14). 662
}

Since then, the utilization of cell phones has developed from simply messaging and calling to multimedia related capacities, video gaming, productivity tools, and travel guides. This present paper proposes a development of mobile application in order to enhance and attract tourists to visit the tourismdestinations. In this study, the technologies used are geofence and proximity beacon which can be placed at any attractive points programmed to deliver information when tourists are in proximity ranges of the beacon transmission signal. In addition, the information will be automatically pushed and displayed in the application. This study was conducted at Melaka Zoo, Malaysia.

This paper reviews related articles on contextual awareness, location-based services, proximity beacon, geofence, mobile cloud computing, and tourism industry in Section 2. Section 3 describes the methodology of this study. Findings and results of all tests conducted are presented and discussed in Section 4. Section 5 concludes this study.

\section{Related literature}

This section discusses several topics that relate to this study, including contextual awareness, location-based 
service and proximity, geofence, mobile cloud computing, and tourism industry.

2.1Contextual awareness, location-based service, and proximity

By and large, context alludes to the information encompassing the user, for example, area, time preference, and others [6]. By joining contextual awareness with mobile applications, another sort of virtual cooperation and new experience to the usercan be made. Contextual awareness is basic for mobile applications since it may enhance the administrative features served to application users. In addition, relevant data may be utilized in triggering a particular activity. Besides, the main part of contextual awareness is the user's location awareness [7, 8]. Location Based Service (LBS) is an assistance that conveys data dependent on the Location Based Service $[9,10]$. The headway of innovations and wireless communication makes the LBS a well-known "killerapplication" [11]. There are two fundamental discussions in the LBS which are location and proximity.

Location is an exact, unmoving spot which is generally characterized by a geographical coordinates system while proximity is not a flat-out area which typically alludes as a separation that it directionless [12]. Location and proximity are normally utilized reciprocally, in any case, both of the terms work diversely and are utilized in various fields. A Bluetooth Low Energy (BLE) guide is a gadget that discharges a sign of BLE to a mobile device nearby $[13,14,15]$. Since BLE attracts a little force request for the beacon to work, the beacon can keep going long for quite a long time upon its setups $[16,17]$. The BLE beacon can work up to around 100 meters. Be that as it may, because of dividers and different sorts of physical obstructions, the separations it can reach will be influenced. The beacon emits BLE packets to the surrounding with different protocols based on the usage. There are many types of protocol that are introduced so that the beacon can be integrated with smartphone platforms [10]. The most popular protocols are iBeacon and Eddystone. Though, in early years of the introduction of iBeacon protocol, it was only used in an Apple-environment only, but recently, it can also be used on the Android platform [18].

\subsection{Geofence}

Geofence empowers distant observing of geographic regions encompassed by a virtual fence (geo-fence), and automatic detections when it tracks portable items that enter or exit from these regions [14, 19]. Geo- fence applications and tools screen the gadgets or other actual articles that enter or exit from the set up geo-fenced territories and provide administrators with alarms when there is an adjustment in the status of the gadget $[10,19,20]$. The Global Positioning System (GPS) is a framework dependent on the Global Navigation Satellite System (GNSS) that gives a reliable location and time data consistently regardless of the climate situations worldwide.

\subsection{Mobile cloud computing}

Mobile Cloud Computing (henceforth, MCC) is characterized as the accessibility and capacity of cloud computing services in a portable climate. Following the concept of Cloud Computing which emerged in 2007, the term Mobile Cloud Computing was later presented. Because of the restriction of cell phones, by offering ideal types of assistance for mobile users, MCC consolidates the components of mobile networks and cloud computing. In MCC, all the information and complicated computing modules can be prepared in clouds and cell phones do not have to bother with amazing setups like CPU speed, the memory limit, and processing power [21-23].

\subsection{Tourism destination}

Smart Zoo is derived from the concept of smart city, where the integration and combination between tourism and information and communication technology [15, 24-26]. One of the new technologies that is emerging in the world is the Internet of Things (IoT) that can help improve the tourism experience of visitors in a tourism destination [24, 27-31]. Subsequently, an effective tourist destination is able to produce benefits constantly through giving the best touristic experience to the vacationers so they make the most of their stay at the particular travelling location [24, 32-34].

Generally, tourists visiting the zoo intend to explore and learn about the animals. There are various common ways of disseminating information to tourists which include producing the engraved version of the information on plaques, stones, or signboards $[25,26$, $33,34]$. This kind of implementation has a limitation because the amount of information that can be displayed depends on the size of the available surface.

Another alternative is to search through the internet of which not many tourists are interested to make [35]. Another method of getting data is through the tour guides or the curators. Nonetheless, tourists are regularly neutral on account of the manner in which 
they gain the information from tour guides and curators to be monotonous and unattractive [29].

\section{Research methodology}

In this section, the methodology is divided into three phases, namely feasibility study and requirement analysis, design and developments, and testing [36].

\subsection{Feasibility study and requirement analysis}

The research teamhad conducted a short interview and site visit to collect information about Melaka Zoo which is required for this study. Information such as the number, names, and the arrangement of the exhibits were recorded for the purpose of beacon arrangement at the zoo. Besides, information displayed at each exhibit also was captured during the site visit and later be inserted into the beacon database. During this phase, the type of proximity beacon was identified. Based on the analysis that was carried out at the site, RadBeacon is chosen to be used in this present study.

\subsection{Design and development}

There are three main activities involved in this phase in order to cater the objective of this study.

- System architecture design

The system architecture illustrates the setup of the project and how it works. Figure 1 shows the system architecture of the prototype. The application is created in an Android platform and it requires an Android smartphone to execute the modules for the visitors, the website for the admin, proximity beacon, internet, firebase database, and global positioning system to arrange effectively. The beacon is expected to communicate the BLE packets that are modified to play out specific tasks. The smartphone and the site are utilized as a platform for the user-interfaces. The GPS coordinates captured during the planning are utilized for sending alarms to the user when they are approaching the zoo zone. In the interim, the free-base database is utilized to store the back-end data.

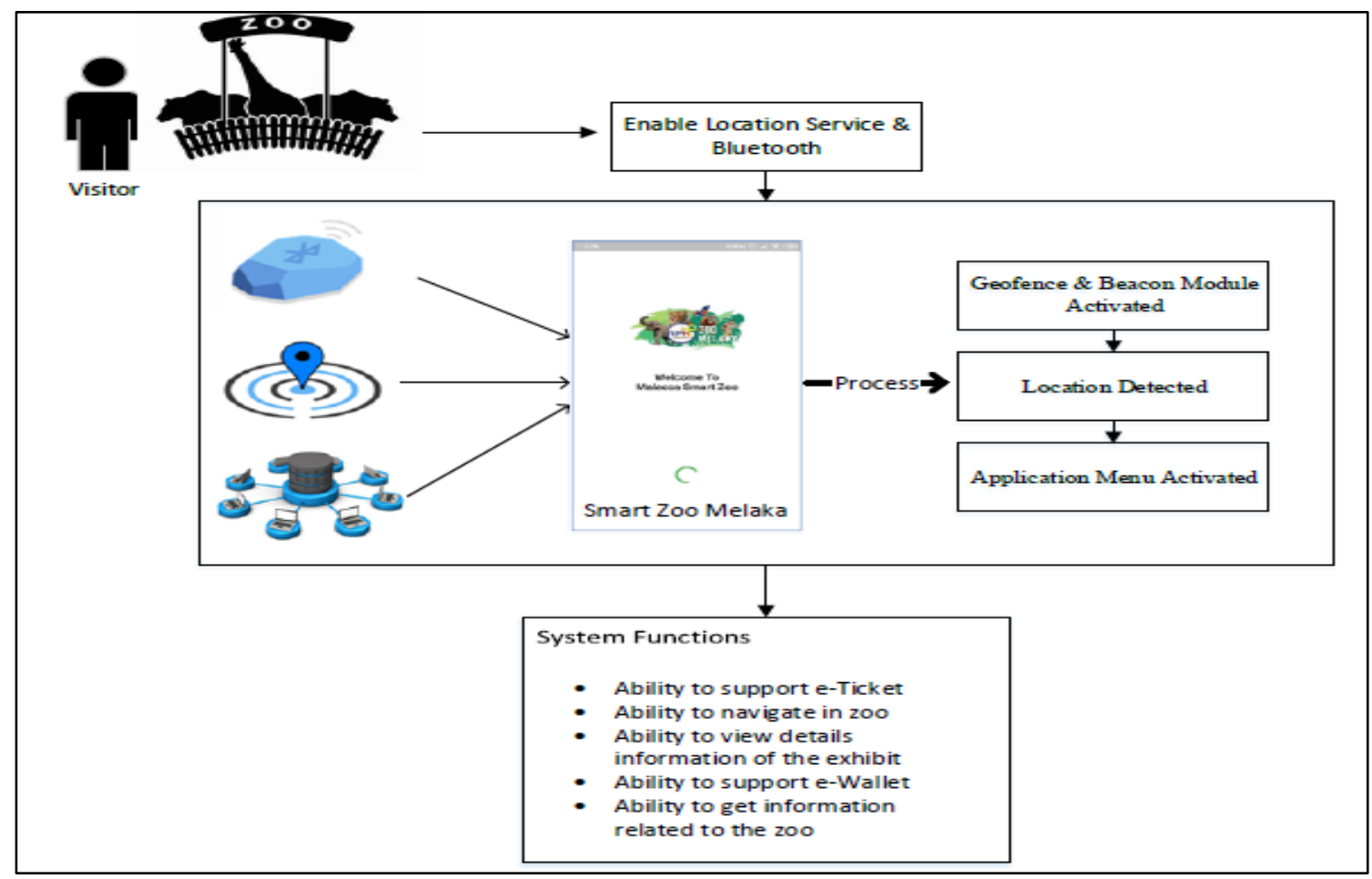

Figure 1 System architecture

\section{- Zoo Mapping}

The layout of Zoo Melaka was captured using Google Maps Application Programming Interface (API) as depicted in Figure 2. In completing this, the researchers walked around the zoo area with the mobile device to capture the track of the zoo. The process of mapping was repeated for three times to get the best mapping for the application.

- Application flowchart and interfaces

The application interfaces are developed based on the designed flowchart of the developed application. Firstly, based on Figure 3, the application should 
begin with an appearance of a dialog box asking for permission to enable location service and Bluetooth. Once the user enables the location service and Bluetooth, the application should be able to detect the location of the user whereby notifications from geofence module will appear. The application menu should be launched and working properly.

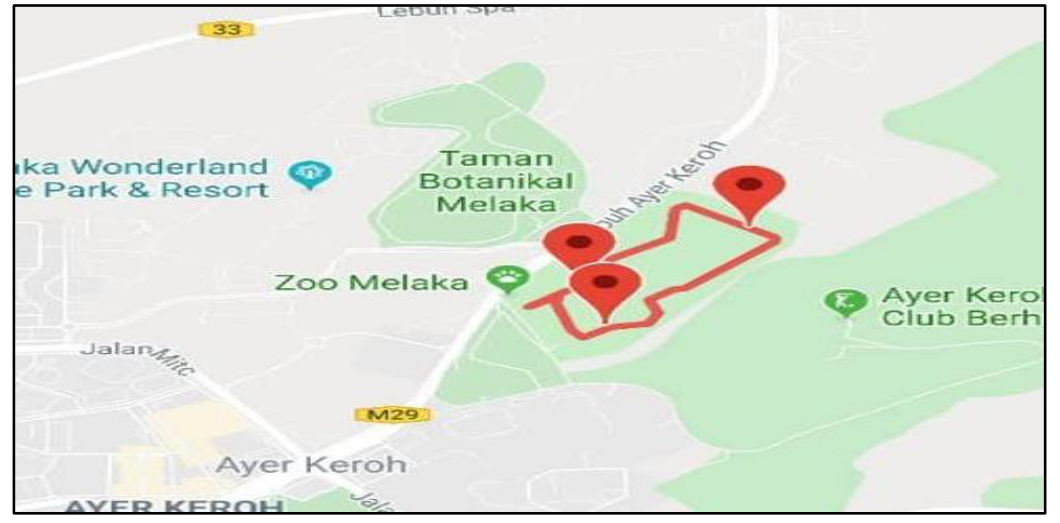

Figure 2 Mapping activity

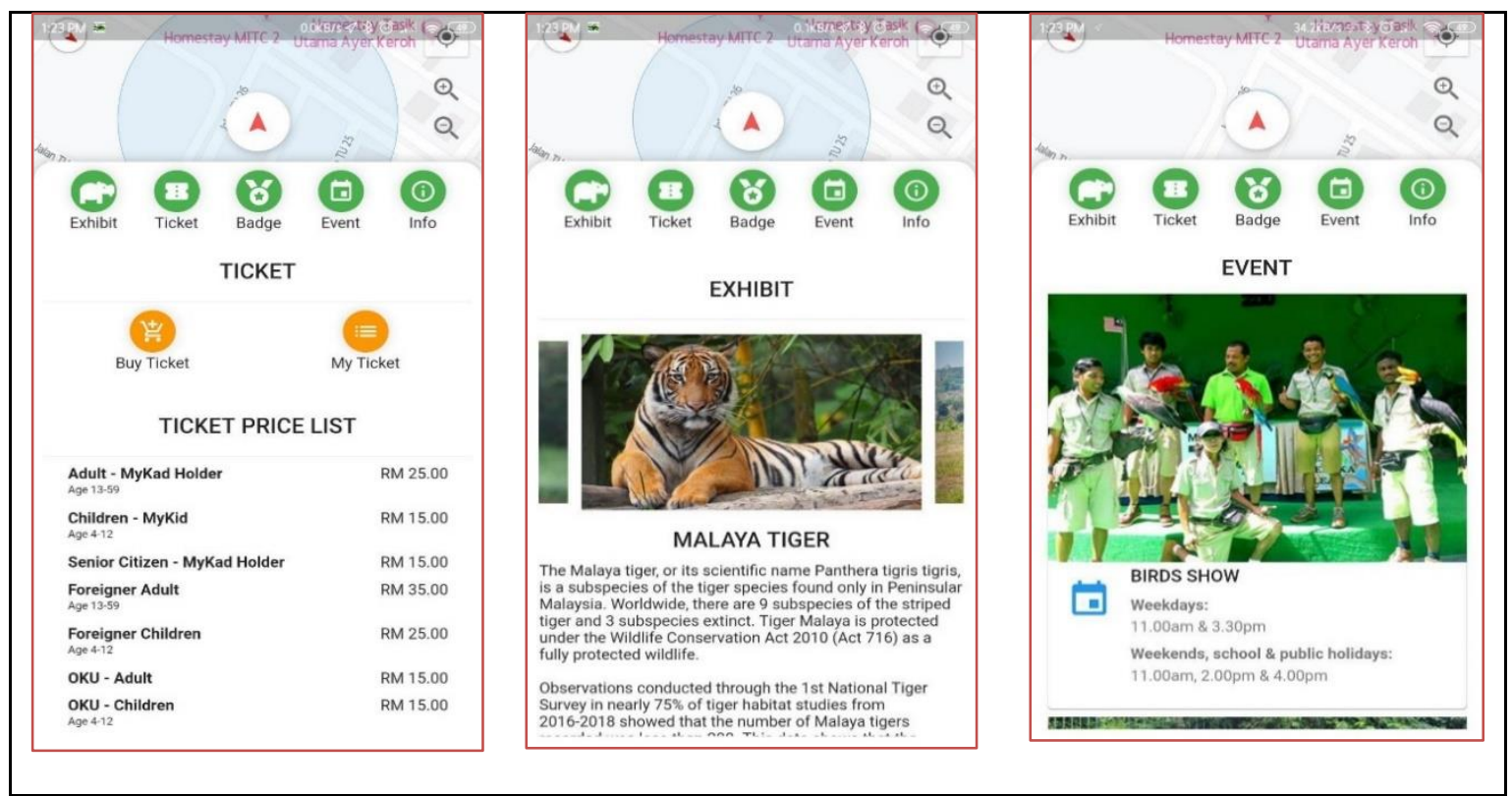

Figure 3 System prototype

\subsection{Testing}

This phase involves the experimental setup for conducting functionality testing and network performance testing. There are two main activities conducted in this phase; systemtesting that consists of functional testing and network performance testing. For functional testing, the development application was tested based on all functions available in the application. Meanwhile, for network performance testing, there were three experiments conducted; geofence accuracy testing, BLE delay testing, and responding time based on two different carriers.

\section{Results and discussion}

This section discusses the results and findings gained from the tests that were conducted on the developed application at Melaka Zoo.

\subsection{Functionality testing}

The usefulness of the system was tried for three times (T1, T2, T3) in light of the menu provided in the 
Alya Geogiana Buja et al.

prototype to ensure the capacity meets the prerequisite and turns out accurately for the user. The result acquired is portrayed in Table 1 , demonstrating that the development application was working appropriately.

Table 1 Functionality test results

\begin{tabular}{|c|c|c|c|}
\hline Component & T1 & T2 & T3 \\
\hline The application is launched when the user approaches and is in the area (geofence) & Pass & Pass & Pass \\
\hline $\begin{array}{l}\text { Information about the animals displayed when the user approaches and is in the area of the exhibit } \\
\text { (proximity beacon) }\end{array}$ & Pass & Pass & Pass \\
\hline The user is able to purchase using the application & Pass & Pass & Pass \\
\hline The user is able to collect badges & Pass & Pass & Pass \\
\hline The user is able to know what is the current activity or live performance & Pass & Pass & Pass \\
\hline
\end{tabular}

\subsection{Network performance testing}

The first experiment conducted for the network performance testing is the geofence accuracy test. The objective of the geofence accuracy test is to determine either the geofence module works properly or not. Table 2 shows the results of the geofence accuracy. The testing was conducted for three times (T1, T2, T3) for each of the three identified cases which are when the user approaches the destination, at the destination, and outside the destination. The application performed well by notifying the user when he/she was approaching and in the area for both CG1 and CG2, and there was no notification appeared when the user was outside the geofence area (CG3).

Table 2 Geofence accuracy test results

\begin{tabular}{lllll}
\hline Case ID & Description & T1 & T2 & T3 \\
\hline CG1 & Approaching the destination & Pass & Pass & Pass \\
\hline CG2 & At the destination & Pass & Pass & Pass \\
\hline CG3 & Outside the destination / geofence area & Pass & Pass & Pass \\
\hline
\end{tabular}

Table 3 Bluetooth Low Energy (BLE) delay test results

\begin{tabular}{lcccc}
\hline Distance $(\mathbf{m})$ & T1 $(\mathbf{m s})$ & T2 $(\mathbf{m s})$ & T3 $(\mathbf{m s})$ & Average $(\mathbf{m s})$ \\
\hline Less than 10 & 0.200 & 0.210 & 0.210 & $\sim 0.220$ \\
\hline $10-20$ & 0.999 & 1.001 & 0.980 & 1.000 \\
\hline $20-30$ & 1.789 & 1.800 & 1.900 & $\sim 1.800$ \\
\hline $30-40$ & 3.599 & 3.620 & 3.580 & $\sim 3.600$ \\
\hline $40-50$ & 5.788 & 5.800 & 5.801 & $\sim 5.800$ \\
\hline
\end{tabular}

The findings of this project conclude that the RadBeacon was able to transmit the signal up to 51 meters. On 0 meters, the delay was at minimal which is at $\sim 0.220$ second. The delay continued to be below 1 second as it reached 20 meters. However, as the distance reached 30 meters; it started to breach the 1 second barrier which is in $\sim 1.800$ seconds. At 40 meters, the delay was significant which is in $\sim 3.600$ seconds. At 50 meters, the delay was recorded in $\sim 5.800$ seconds. As the distance came to pass 51 meters, the cell phone could not recognize the BLE signal. There are numerous variables influencing the aftereffect of the experiment directed. One of it was on
The BLE delay test was the second experiment conducted for the network performance testing. The purpose of this experiment is to find the delay in the developed application to receive the BLE signal from the beacon relative to the distance. The purpose of the network performance testing is to measure the performance of the proximity beacon in transmitting the signal and the device to accept the signal. The setup of the experiment was using a smartphone and a beacon. The delay is determined as the user pressed the 'scan BLE signal' button until the phone receives the BLEsignal. The distances between the smartphone and the beacon was recorded and conducted for several times. The results obtained in this test are depicted in Table 3 and Figure 4. the grounds that the BLE signal had to go through a significant distance as this will bring about a portion of the signal to be deferred and turn out to be slower for transmission. As the distances escalate, the time taken for the signal to proliferate will likewise escalate. The third experiment directed for network performance testing was to test the reaction time of the mobile application to bring information from the database utilizing various transporters when the mobile application recognizes the beacon signal. In order to get an actual result, the experiment was conducted using the same smartphone, but with two different carriers which were Digi and Celcom. The 
distance between the smartphone and the beacon was also the same which is at 0 meters. The response time of the mobile network performance is determined as the time taken for the mobile application to load all its contents when the BLE signal is received. The experiment was conducted for three times in order to get the average results. The results of the experiment are shown in Figure 5.

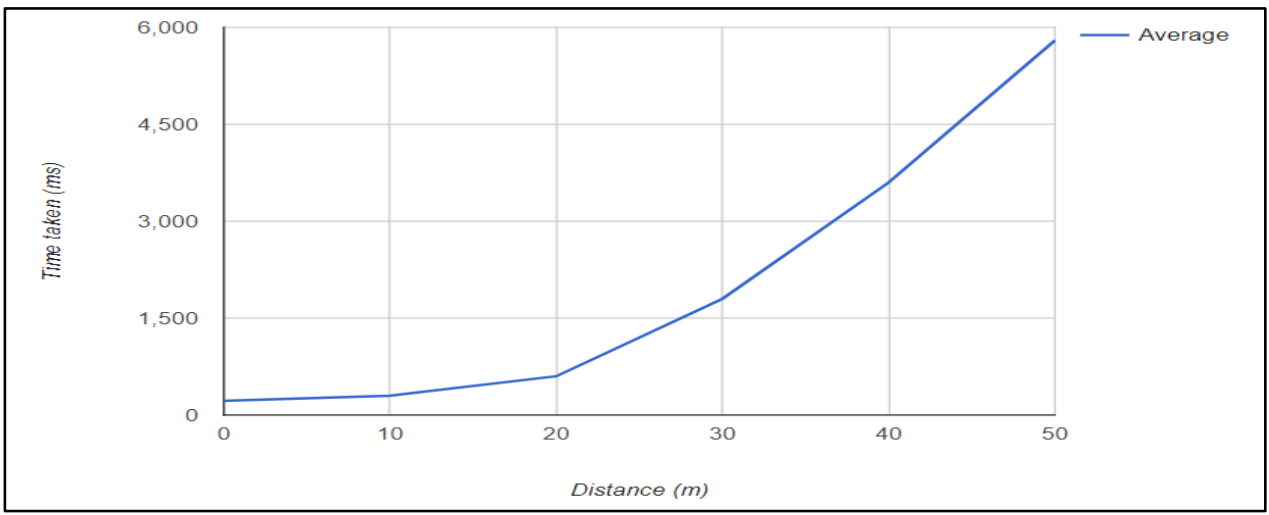

Figure 4 Bluetooth low energy (BLE) delay

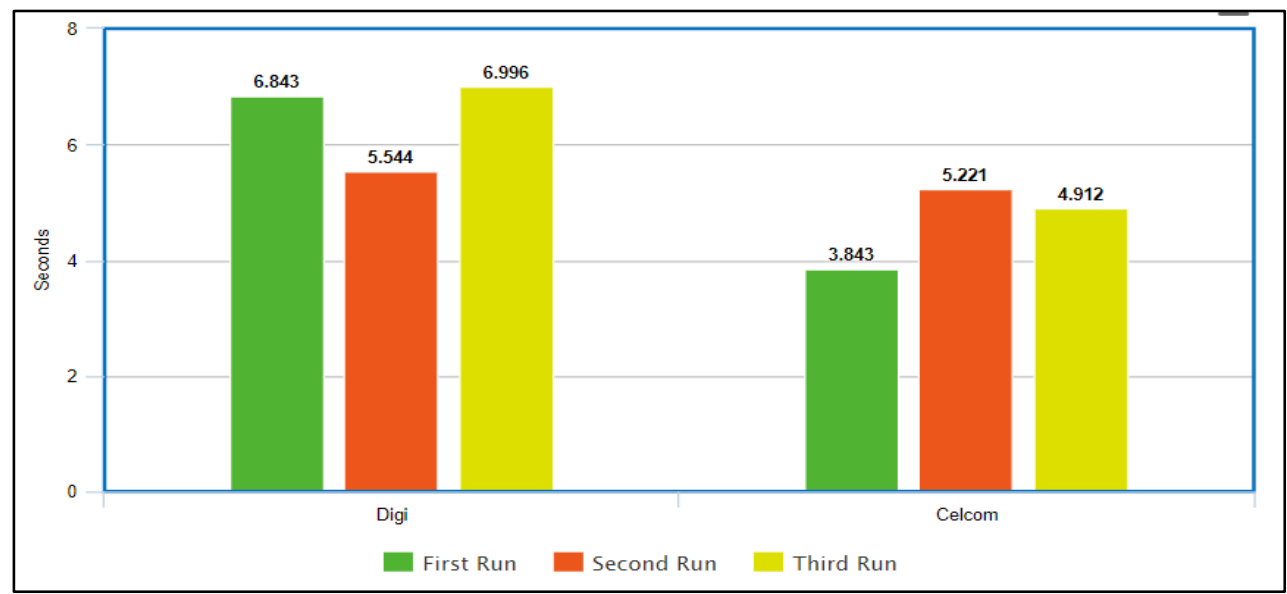

Figure 5 Response time of the carriers

\section{Conclusion}

In this research, the main objective was to develop a mobile application that utilizes mobile technologies; geofence, and Bluetooth is using proximity beacon. Thus, this study attempted to deliver the information based on the context awareness provided by the location-based service and proximity beacon. The application was able to create an interactive environment and better experience for visitors. In conclusion, the researchers hope that the tourism destination can attract visitors to come as the developed prototype was tested for functionality of a network performance at Melaka Zoo. Both testings obtained positive output results which indicated that the design and developed prototype worked properly. For future work, this application can be improved to be applied in other related applications such as the smart campus application and be extended to the iOS platform.

\section{Acknowledgment}

Sincere appreciation goes to Universiti Teknologi MARA Cawangan Melaka for the support given to this research endeavour, TEJA: Internal Grant (GDT2020-14).

\section{Conflicts of interest}

The authors have no conflicts of interest to declare.

\section{References}

[1] https://webunwto.s3.eu-west-1.amazonaws.com/s3fspublic/2020-

03/21_4_Tourism_COVID19_Data_Coalitionpptx.pdf . Accessed 10 August 2020.

[2] https://www.tourism.gov.my/media/view/malay sia-stourism-performance-records-negative-growth-of-786-from-jan-sep-2020. Accessed 10 August 2020. 
[3] Iyobe M, Ishida T, Miyakawa A, Sugita K, Uchida N, Shibata Y. Proposal of a virtual traditional japanese crafting presentation system mobile edition. In international conference on innovative mobile and internet services in ubiquitous computing 2016 (pp. 120-5). IEEE.

[4] Ishida T, Li H. Implementation and evaluation of a web-based regional culture inheritance support system. International Journal of Web and Grid Services. 2020; 16(1):39-62.

[5] Islam R, Islam R, Mazumder T. Mobile application and its global impact. International Journal of Engineering \& Technology. 2010; 10(6):104-11.

[6] Pashtan A, Blattler R, Andi AH, Scheuermann P. CATIS: a context-aware tourist information system. e 4th international workshop of mobile computing, 2003.

[7] Marmasse N, Schmandt C. Location-aware information delivery with commotion. In international symposium on handheld and ubiquitous computing 2000 (pp. 157-71). Springer, Berlin, Heidelberg.

[8] Sykes ER, Pentland S, Nardi S. Context-aware mobile apps using iBeacons: towards smarter interactions. In CASCON 2015 (pp. 120-9).

[9] Husain W, Dih LY. A framework of a personalized location-based traveler recommendation system in mobile application. International Journal of Multimedia and Ubiquitous Engineering. 2012; 7(3):11-8.

[10] https://www.cmo.com.au/article/685797/reportlocation-based-marketing-increasingly-valuable-dataaccuracy-remains-question/. Accessed 10 August 2020.

[11] Huang H, Gartner G, Schmidt M, Li Y. Smart environment for ubiquitous indoor navigation. In international conference on new trends in information and service science 2009 (pp. 176-80). IEEE.

[12] Sandberg LS, Busch FN. Psychotherapy and pharmacotherapy: a contemporary perspective. Psychody namic Psychiatry. 2012; 40(3):505-32.

[13] Law CH. Location aware system using bluetooth low energy beacons (Doctoral dissertation, UMP). 2014.

[14] Vargas MH. Indoor navigation using bluetooth low energy (BLE) beacons. Turku University of Applied Sciences. 2016.

[15] Spachos P, Plataniotis K. Ble beacons in the smart city: applications, challenges, and research opportunities. IEEE Internet of Things Magazine. 2020; 3(1):14-8.

[16] Andersson T. Bluetooth low energy and smartphones for proximity-based automatic door locks. Digital Scientific Archive.2014.

[17] Cheng RS, Hong WJ, Wang JS, Lin KW. Seamless guidance system combining GPS, BLE beacon, and NFC technologies. Mobile Information Systems. 2016:1-12.

[18] Deraman NA. I-campus: towards the information integration for uitm cawangan melaka implementation of smart campus. Turkish Journal of Computer and Mathematics Education. 2021; 12(5):1699-709.

[19] https://teltonika-gps.com/downloads/en/usecases/geofence-solution-in-the-event-of pandemic.pdf . Accessed 10 August 2020.
[20] Özdemir Z, tuğrul B. Geofencing on the real-time GPS tracking system and improving GPS accuracy with moving average, kalman filter and logistic regression analysis. In international symposium on multidisciplinary studies and innovative technologies 2019 (pp. 1-6). IEEE.

[21] Christian M. Mobile application development in the tourism industry and its impact on on-site travel behavior. Modul Vienna University. 2015.

[22] Buja AG, Latip SF. The direction of lightweight ciphers in mobile big data computing. Procedia Computer Science. 2015; 72:469-76.

[23] Li H, Lan C, Fu X, Wang C, Li F, Guo H. A secure and lightweight fine-grained data sharing scheme for mobile cloud computing. Sensors. 2020; 20(17):1-17.

[24] Ahn B. Construction of system to support intelligent coffee shop using IoT. International Journal of Recent Technology and Engineering.2019; 8(2S6): 342-6.

[25] Kadhim W, Al-qaraawi SM. Design and implementation of an interactive system for zoo application using smart mobile phone and or code. International Journal of ResearchGRANTHAALAYAH. 2020; 8(4):285-96.

[26] Widarti E, Emanuel AW. Mobile application design for heritage tourism uses gamification approach in Indonesia. International Journal of Engineering Pedagogy. 2020; 10(5):89-102.

[27] Tussyadiah I, Inversini A. Information and communication technologies in tourism. In proceedings of the international conference in Lugano, Switzerland 2015.

[28] Rodrigues D, Luis-Ferreira F, Sarraipa J, Goncalves R. Behavioural monitoring of alzheimer patients with smartwatch based system. In international conference on intelligent systems 2018 (pp. 771-5). IEEE.

[29] Hiramatsu Y, Sato F, Ito A, Hatano H, Sato M, Watanabe $\mathrm{Y}$, et al. Designing mobile application to motivate young people to visit cultural heritage sites. International Journal of Social and Business Sciences. 2017; 11(1):121-8.

[30] Buyya R, Dastjerdi AV. Internet of things: principles and paradigms. Elsevier; 2016.

[31] Badawood A, Albadri H. Proposed systems for knowledge sharing between the faculty concentrating in the middle east and gulf region area. International Journal of Engineering \& Technology. 2018; 7(3.13):171-5.

[32] Bahtiar AR, Segara AJ. Design of smart gamification in village tourism: an Indonesian case study. International Journal of Engineering Pedagogy. 2020; 10(1):82-93.

[33] Coghlan A, Carter L. New product design: creating a digital vr game to promote the conservation of naturebased tourism attractions. The Emerald Handbook of ICT in Tourism and Hospitality. 2020. p.167-79.

[34] Fanani L, Brata KC, Brata AH, Fauzi MA. Usability evaluation of mobile-based application for Al-Quran writing learning with gamification. In international conference on sustainable information engineering and technology 2019 (pp. 276-9). IEEE. 
[35] Sasaki A, Ito A, Hayashi R, Hiramatsu Y, Ueda K, Harada $\mathrm{Y}$, et al. A study of psychological approach to design sightseeing support mobile application. In international conference on intelligent engineering systems (INES) 2018 (pp. 87-92). IEEE.

[36] Kramer M. Best practices in systems development lifecycle: an analyses based on the waterfall model. Review of Business \& Finance Studies. 2018; 9(1):7784.

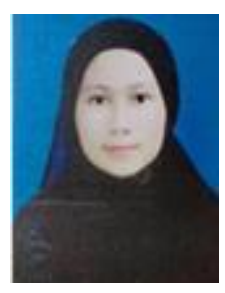

Alya Geogiana Buja is a Senior Lecturer at the Faculty of Computer and Mathematical Sciences in Universiti Teknologi MARA (UiTM) Cawangan Melaka. She is a PhD holder in the field of Information Security and graduated from Universiti Teknikal Malaysia Melaka (UTEM), MSc in Computer Science and BSc in Netcentric Computing from Universiti Teknologi MARA (UiTM). Her research interests are Networking and Information Security, Cryptanalysis and Cyber Security.

Email: geogiana@uitm.edu.my

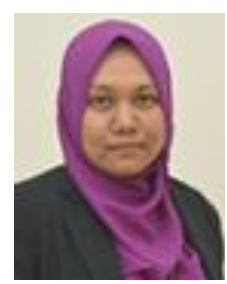

Noor Afni Deraman is currently a lecturer at Faculty of Computer and Mathematical Sciences, Universiti Teknologi MARA (UiTM) Melaka. She obtained her Bachelor's degree in Computer Science majoring in Software Engineering from Universiti Sains Malaysia (USM). She completed her Master's degree in Science (Computer Science) in 2006. Her research interest is in Data Science and Artificial Intelligence.

Email: noora465@uitm.edu.my

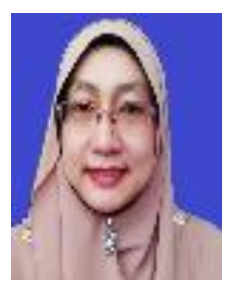

Khyrina Airin Fariza Binti Hj Abu Samah is a senior lecturer from Universiti Teknologi MARA (UiTM), Melaka Jasin Campus. She has 13 years of working experience in the Information Technology field in the semiconductor industry before joining UiTM. She has Diploma, Bachelor's Degree and Master's Degree in Computer Science and PhD in Information Technology. Her research interest in Artificial Intelligent, Operational Research, Algorithm Analysis, Clustering and Optimization, Evacuation Algorithm, Internet of Things (IoT) and Sentiment Analy sis. Email: khyrina783@uitm.edu.my

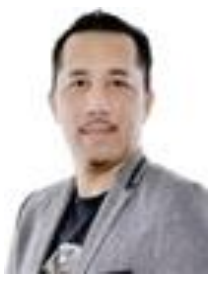

Mohd Nor Hajar Hasrol Bin Jono obtained his $\mathrm{PhD}$ in 2016. At present, he is working as a senior lecturer at the Faculty of Computer Science and Mathematics at Universiti Teknologi MARA (UiTM) Melaka, Malay sia. Now in the field of administration, he currently holds the position of Deputy Rector of Student Affairs UiTM Melaka. Previously, he was the Head of Training Division, Head of Systems Division and also Fellow at the i-Learn Center under the Academic Affairs Division, UiTM Shah Alam.

Email: hasrol@uitm.edu.my

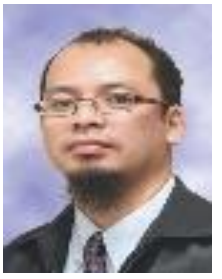

Mohd Ali Mohd Isa is a senior lecturer at MARA University of Technology (UiTM). Previously, he was the Head of Department for System Management at the Center of learning UiTM since 2005 until 2015. He was responsible for the setting up of the first Learning Management System for UiTM and oversee the working of the system for 10 y ears. Currently he is teaching the subjects of Web Technology and Information Security, which are two of his research areas.

Email: mohdali@uitm.edu.my

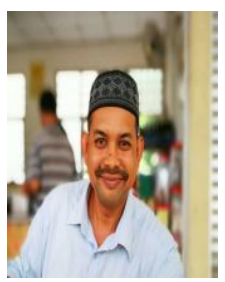

Shahadan Bin Saad has a diploma in computer science and a bachelor's degree in science (data communication and networking), both from the Universiti Teknologi MARA (UiTM), Malaysia. Academically, he is a free/open source software (FOSS) enthusiast and teaches various subjects in computer science and networking at UiTM. He also holds a M Sc IT from Universiti Utara M alay sia (UUM), Malay sia. He was the programmer at UUM. After completing his master's degree, he started his role as an academic instructor and has been working with many languages, such as $\mathrm{C}, \mathrm{C}++$, Fluter, Java, and Python. He is very excited by using the Flutter to build Android applications.

Email: shahadan@uitm.edu.my 